\title{
A IMPORTÂNCIA DO PSICOPEDAGOGO INSTITUCIONAL FRENTE A DIFICULDADE DE APRENDIZADO.
}

\author{
Mariana Aparecida Grillo, Joel Augusto Oliveira Sanchez \\ Universidade do Oeste Paulista - UNOESTE, Presidente Prudente, SP. E-mail: mary.loirinha@hotmail.com
}

\begin{abstract}
RESUMO
A pesquisa desenvolvida tem como objetivo apresentar a escola como um local de promoção ao conhecimento, onde o educando terá a oportunidade de apropriar-se dos conteudos necessários para desenvolver-se e ter uma vida social. Contudo,o aluno pode apresentar dificuldade de aprendizagem em virtude da falta de inclusão escolar, ou por problemas familiares e pessoais. Nesse sentido surge a ação do psicopedagogo na busca de respostas para cada particularidade. Com um trabalho investigativo, é possível criar métodos de trabalho com esse aluno para que sua dificuldade seja sanada. Diante dos novos paradigmas escolares, é fundamental o trabalho do psicopedagogo como um intermediador no processo educativo. Neste contexto este profissional ganha o papel de renovar os conceitos de ensino e de adequar as metodologias e práticas, para que nessa era informatizada onde a informação é transmitida em tempo real, o aluno seja alcançado em suas dificuldades, anseios e receios. Sendo assim, este trabalho apresenta dentro da pesquisa analítica, bibliográfica e exploratória uma reflexão sobre tais fatos, consolidando o papel do psicopedagogo, e concluindo atraves deste estudo a finalidade deste profissional que irá desenvolver seu trabalho favorecendo e orientando o processo de ensino e aprendizagem e desenvolvimento humano.
\end{abstract}

Palavras-chave: Psicopedagogia institucional. Parceria institutional. Dificuldade de Aprendizado.

\section{THE IMPORTANCE OF INSTITUTIONAL PSYCHOEDUCATORS IN THE FACE OF THE DIFFICULTY OF LEARNING}

\begin{abstract}
The research developed aims to present the school as a place of promotion to knowledge, where the educating will have the opportunity to take ownership of the necessary contents to develop and to have a social life. However, the student may experience difficulty in learning because of the lack of school inclusion, or for family and personal problems. In this sense comes the action of the Psychoeducator in the search for answers for each particularity. With investigative work, it is possible to create working methods with this student so that their difficulty is remedied. In the face of the new school paradigms, the work of the psychoeducator is essential as an intermediator in the educational process. In this context this professional gains the role of renewing the concepts of teaching and of adapting the methodologies and practices, so that in this computerized era where the information is transmitted in real time, the student is achieved in its difficulties, yearnings and fears. Thus, this work presents within the analytical, bibliographic and exploratory research a reflection on such facts, consolidating the role of the Psychoeducator, and concluding through this study the purpose of this professional that will develop its Work favoring and guiding the process of teaching and learning and human development.

Keywords: Institutional psychopedagogy. Institutional partnership. Learning disability.
\end{abstract}




\section{INTRODUÇÃO}

A atuação do Psicopedagogo na escola torna-se um importante papel para um trabalho de intervenção nas dificuldades de aprendizagem, essa mediação nas instituições escolares tem como foco o trabalho de assessoria e prevenção, isto é, tem por objetivo analisar aspectos desde à construção do conhecimento até as observações dos aspectos cognitivos e afetivos que envolve o aluno.

Sabe-se que a função da escola está em propiciar ao aluno um mundo de informações que o possibilite a ter uma vida social, a desempenhar suas funções enquanto cidadão, a expressar-se e se capacitar. Dessa forma, o papel da escola vai além de ensinar uma grade curricular, ela desempenha a função de cuidar da criança como um segundo lar (NOVOA, 1995).

Compreende-se também que o conhecimento se dá de forma harmoniosa e equilibrada nas diferentes áreas: cognitiva, emocional e social, sendo assim a Psicopedagogia torna-se um processo pelo qual o profissional junto a escola tenha um olhar minucioso no ponto de vista de quem ensina e de quem aprende, abrangendo o contexto escolar, familiar e social dos envolventes.

Neste sentido essa pesquisa tem como intuito principal buscar informações do papel do Psicopedagogo junto a escola no desenvolvimento das aprendizagens dos alunos.

\section{METODOLOGIA}

Este trabalho tem como metodologia o levantamento bibliográfico para o desenvolvimento da investigação, constituindo-se numa abordagem de caráter qualitativo, exploratório, descritivo e explicativo, fazendo-se uso da pesquisa documental. Segundo Marconi e Lakatos, (apud Perske, 2004, p. 10) :

A pesquisa bibliográfica é o levantamento de toda a bibliografia já publicada, em forma de livros, revistas, publicações avulsas e imprensa escrita. A sua finalidade é fazer com que o pesquisador entre em contato direto com todo o material escrito sobre um determinado assunto, auxiliando o cientista na análise de suas pesquisas ou na manipulação de suas informações. Ela pode ser considerada como o primeiro passo de toda a pesquisa científica.

Sendo assim, a pesquisa bibliográfica abrange a leitura, análise e interpretação de livros, periódicos, documentos mimeografados ou xerocopiados, mapas, fotos, manuscritos, etc.

Todo material utilizado foi selecionado, a partir do tema proposto, na qual foi possível estabelecer um objetivo de leitura.

\section{Contribuições da Psicopedagogia Institucional}

O atual trabalho busca compreender a finalidade da educação como algo indissociável a vida humana, porem para os sujeitos que buscam o conhecimento ele pode ser considerada um desafio ou algo dificultoso, levando assim a baixa auto-estima, a falta de interesse e até mesmo a comportamentos fora do padrão de vivência na escola. Para isso surge o papel do Psicopedagogo Institucional, sendo como um fio condutor ele estabelece um relacionamento de parceria, de modo a contribuir na formação integral da criança.

O Código de Ética da Psicopedagogia explica:

É definida como "um campo de atuação em Educação e Saúde que se ocupa do processo de aprendizagem considerando o sujeito, a família, a escola, a sociedade e o contexto sócio-histórico utilizando processos próprios, fundamentados em diferentes referenciais teóricos".

Sendo assim, esse campo de atuação profissional abrange o processo de aprendizagem como algo indissociável do contexto familiar e escolar, englobando diferentes fundamentos para a solução do "problema". 
Saber agir com a dificuldade da criança em aprender é um desafio constante, porque nem sempre a resposta da questão está na metodologia de ensino, ou na política escolar. Muitas vezes, fatores que ultrapassam as paredes da escola interferem na concentração do educando de forma a deixa-lo ansioso e/ou distraído (BOSSA, 2000).

Se a escola não souber como responder a distração do aluno, o problema inicial pode torna-se o começo de outros. A criança começa a achar-se incapaz de aprender, e qualquer tentativa de abordagem malsucedida é respondida com agressão e indisciplina como forma de desafio ao professor (FAGALI, 2001).

Nesse sentido a busca pela compreensão do profissional que irá contribuir para o processo de ensino e aprendizagem se faz presente nesta pesquisa, pois o grande desafio das instituições de ensino nos dias atuais é despertar nos alunos o desejo e a vontade de aprender.

Segundo Barbosa ( apud Pontes, 2010)

\begin{abstract}
"Transformar a aprendizagem em prazer não significa realizar uma atividade prazerosa, e sim descobrir o prazer no ato de: construir ou de desconstruir o conhecimento; transformar ou ampliar o que se sabe; relacionar conhecimentos entre si e com vida; ser co-autor ou autor do conhecimento; permitir-se experimentar diante de hipóteses; partir de um contexto para a descontextualização e vice-versa; operar sobre o conhecimento já existente; buscar o saber a partir do não saber; compartilhar suas descobertas; integrar ação, emoção e cognição; usar a reflexão sobre o conhecimento e a realidade; conhecer a história para criar novas possibilidades".
\end{abstract}

Ou seja, a aprendizagem vai além do prazer em realizar um atividade considerada "atraente", transformar uma aprendizagem prazerosa significa dividir descobertas, interagir e compartilhar ideias, criando novas possibilidades.

O Psicopedagogo sendo um profissional adaptado a trabalhar nessa área, exerce o papel de analisar o processo de aprendizagem e suas dificuldades, investigando o processo de aquisição de conhecimento do aluno, com a finalidade de entender e estudar aquele indivíduo na sua individualidade e outros aspectos ligados a ele, visando a compreensão do problema ou do distúrbio apresentado. Seu trabalho parte de um diagnóstico onde irá ajudar o educando e as pessoas envolvidas a vencer os desafios com maior autonomia e flexibilidade.

O psicopedagogo aprende em teoria a unir pais, professores e gestores para juntos buscarem uma forma de resolucionar a problemática que interfere no desempenho do aluno. Na prática, a colaboração geralmente torna-se inviável devido aos conflitos de interesse, agenda e impossibilidade instrumental (SMITH \& STRICK, 2001).

Smith e Strick (2000) ainda explicam que o trabalho do psicopedagogo acaba se tornando desafiador a medida que seu intuito passa a investigar metodologias e políticas que possibilitem a inclusão, o desestimulo a descriminação e a construção das adaptações sistemáticas na busca da inclusão e da equidade.

O auxílio ao educando por parte do psicopedagogo vai além de ajudá-lo a superar as problemáticas internas que dificultam seu aprendizado. Ele está para estimular o interesse em aprender, fazendo-o compreender ser essa uma condição natural da sua identidade humana (FREIRE, 1996).

Com a psicopedagogia é possível compreender como o educando, enquanto parte de uma engrenagem submetida ao ensino aprendizagem, faz uso de seus recursos para apropriar-se do conhecimento apresentado seja pelo currículo exposto em sala de aula, seja pelo convívio social (KLEIMAN \& MORAES, 2003).

A dificuldade em aprender não está apenas ligada a alguma deficiência física ou mesmo mental. Fatores emocionais têm apresentado uma importância vital para reações aversivas ao ato de aprender (FAGALI, 2001).

Aprender a entender-se enquanto pessoa, conscientizando-se de como os fatores interferem em seu cotidiano, e a forma como eles podem ser superados para que a limitação seja 
enfraquecida é o método mais viável para que a psicopedagogia alcance seu intento (FREIRE, 1996).

Para isso, o profissional irá atuar de forma a resgatar a autonomia do educando, dando-lhe meios favoráveis ao seu desenvolvimento, de forma positiva restaura a auto estima e leva ao aluno enfrentar suas dificuldades com preparo.

A confiança necessária para desempenhar essa missão depende de tempo e do apoio escolar e familiar, visando compreender nesse percurso como ele aprende.

Sabe-se também que a família tem um papel importante no desenvolvimento do educando, pois contribui para que as primeiras aprendizagens necessárias se realizam, o bom relacionamento familiar também favorece o processo educativo, nesse sentido a família deve estar presente no acompanhamento da vida escolar do aluno, tendo a responsabilidade de ajudalo no progresso escolar.

\section{CONSIDERAÇÕES FINAIS}

Ao longo deste artigo buscou-se compreender a importância de um profissional capacitado para agir no processo educativo dos alunos que apresentam algum desfio no desenvolvimento educacional, relatou-se que a função da escola está para promover ao educando as informações que o possibilitem a ter uma vida social e a desempenhar suas funções enquanto cidadão, além de ser apto a expressar-se de forma a ser compreendido.

Explicou-se que em casos onde o aluno não consegue encaixar-se no meio ao qual foi inserido, ele sofre um quadro de exclusão social que abala sua forma de lidar com o aprendizado oferecido em sala de aula, fazendo-o apresentar a dificuldade no aprendizado, e interferindo em seu comportamento. Em alguns casos, é possível observar a rebeldia, o auto isolamento e possivelmente na evasão escolar.

Com tudo, o papel do psicopedagogo é promover ao aluno uma forma dele libertar-se e expressar-se sobre as situações que o levam a apresentar a dificuldade no ato de assimilar o conteúdo proposto em sala de aula. Dessa forma, o educando além de ter apoio emocional, também se vê diante de uma metodologia mais apropriada para ele.

Esclarece também sobre a importância do apoio da família e da escola no desenvolvimento de novas metodologias e políticas de inclusão, bem como trabalhar em parceria com professores e gestores.

Demonstra que o trabalho deve ser executado em parceria pois este requer uma investigação, análise de propostas, e uma execução adequada ao espaço escolar. Onde o resultado final estará em oferecer uma qualidade de ensino a criança, e a superação desta a dificuldade apresentada. $O$ trabalho em equipe com professor e psicopedagogo, pais e alunos tem papel importante no alcance do objetivo primário que é aumentar a aprendizagem, sanar as dificuldades e prevenir possíveis problemas no ato de aprender ler e escrever, socializar e expressar-se, ser autônomo e desenvolver as habilidades.

Conclui-se assim que a psicopedagogia é compreender que o aluno é a última peça de um efeito dominó. Quando este apresenta dificuldade em aprender, ou começa a apresentar um comportamento diferente é necessário investigar, analisar e trabalhar em conjunto com educadores e gestores na busca das causas e na escolha do método mais propicio para sana-la.

\section{REFERÊNCIAS}

BOSSA, N.. Dificuldades de Aprendizagem: o que são? Como tratá-las? Porto Alegre: Artmed; 2000.

FAGALI, H.Q. Múltiplas faces do aprender: novos paradigmas da pós-modernidade. 2a ed. São Paulo: Unidas; 2001. 
FREIRE, P.. Pedagogia da autonomia. Saberes necessários à prática educativa. São Paulo: Paz e Terra, 1996.

KLEIMAN, A.; MORAES, S.E.. Leitura e interdisciplinaridade. Tecendo redes nos projetos da escola. São Paulo: Mercado das Letras, 2003.

NOVOA, A. As organizações escolares em análise. Lisboa: Dom Quixote;1995.

OLIVEIRA, M. K. Vygotsky: aprendizado e desenvolvimento: um desenvolvimento sócio histórico. São Paulo: Scipione, 1997.

PONTES, M.A.I. Atuação psicopedagógica no contexto escolar: manipulação, não; contribuição, sim. Periódicos Eletrônicos em Psicopedagogia, São Paulo, V.27, N 84, Nov., 2010. Dísponivel em: http://pepsic.bvsalud.org/scielo.php?script=sci_arttext\&pid=S0103-84862010000300011

PERSKE, F.C.R. SISTEMAS AGROFLORESTAIS EM PEQUENAS PROPRIEDADES NO MUNICÍPIO DE HULHA NEGRA. 2014. 64f. Monografia- Universidade da Região da Campanha, Bagé, 2004.

SANTA CATARINA. SOCIEDADE BRASILEIRA DE NEUROPSICOPEDAGOGIA. ART 29. Neuropsicopedagogia Institucional e Clínico de 2015. DISPONÍVEL EM: http://www.sbnpp.com.br/neuropsicopedagogo-institucional-e-clinico-artigo-comentado-art-29do-codigo-de-etica-tecnico-profissional/

SMITH, c.; STRICK I. Dificuldades de aprendizagem de a a z. tradução dayse batista - Porto Alegre: Artmed, 2001. 